\title{
A SOCIEDADE ESPANHOLA, VISTA ATRAVÉS DE "LA GITANILLA" (1613).
}

\author{
GISELDA MOTA \\ Licenciada em História pela Faculdade de Filosofia, \\ Letras e Ciências Humanas da Universidade de São \\ Paulo. \\ I. - Cervantes e a Sociedade de seu tempo.
}

Cervantes viveu no período compreendido entre os últimos anos do reinado de Carlos V e de Filipe III, mais precisamente entre 15471616. A Espanha vivia exatamente nesse período uma crise decisiva de poderio. Evidentemente, como aponta Pierre Vilar (1), a localização da crise apenas nesses anos é discutível na medida em que a moeda só se desvalorizou em 1624, e a unidade ibérica se desmantelou em 1640 . Entretanto, desde 1558 prognósticos sombrios eram feitos, por exemplo, por Luís Ortiz (Memorial).

Durante o governo de Filipe II, a situação crítica ficou encoberta por acontecimentos como San Quintin, Lepanto, a chegada de prata das Indias. Por volta de 1600 apenas é que os problemas concretos se tornaram claros: fome em Andaluzia, peste em Castela, problemas demográficos resultantes da grande concentração nas cidades e abandono dos campos, alta do preço dos cereais (1602-1605), prata chegando mais cara etc.

Apesar do contexto econômico-crítico, em contraste com a miséria reinante, o poderio de imensas fortunas foi posto em relevo. $O$ feudalismo e seu grupo representativo (nobreza rural) foram bloqueados, limitados em benefício de um grupo de ascensão. Os reis, embora tentassem preservar as instituições feudais, foram obrigados a vender cargos vitalícios para atender as necessidades da Coroa, originanido dessa forma uma burocracia voraz e venal.

(1). - Vilar (Pierre). - Crecimiento y Desarrollo, Barcelona, Ediciones Ariel, 1964: pp. 432, 435. 
Ao lado da nobreza da Corte, da nobreza rural decadente, dos grupos burgueses comerciantes em vias de ascensão, existia a massa popular trabalhadora que, juntamente com camponeses e artesãos, comportava tipos parasitas (soldados licenciados com pequeno soldo, mendigos), grupos de ciganos, mouriscos e bandoleiros. Em suma, a sociedade espanhola apresentava grupos não integrados, por vezes mesmo discriminados, no processo de produção.

A literatura espanhola funcionou como um verdadeiro registro da situação da sociedade: à picaresca, dentre os gêneros surgidos e apreciados, coube a tarefa de criticar, e ao mesmo tempo sublimar (2) realidades.

E' justamente nesse panorama que surge Cervantes, criador do Quixote, autor frequentemente considerado barroco, mas que, como Pfandl aponta (3) não é barroco no estilo, nas idiéas e nas tendências.

Nesse ambiente em que o rompimento da rigidez do sistema feudal estava se processando, Cervantes conheceu uma existência errante, como muitos de seus contemporâneos: Lope de Vega, El Greco e outros.

De origem modesta viveu em Valadolid, Madrí, Sevilha, Madrí novamente, onde estudou com Juan Lopez de Hoyos. Esteve em Roma e a partir dessa estada é possível tecer considerações sobre sua formação e sua cultura. Participou da batalha de Lepanto, episódio aproveitado pelos governantes para encobrir duras realidades, da qual voltou mutilado. Preso por piratas bérberes permaneceu em Argel durante muitos anos até que sua família, mediante grande esforço, conseguiu o resgate $(1580)$.

Esteve a serviço do rei, conseguiu um cargo de comissário đo abastecimento no período de montagem da Invencível Armada; andou por Andaluzia requisitando trigo e azeite, o que lhe custou a excomunhão. Exerceu também o cargo de cobrador de impostos (1594), sofrendo processos e prisão por inexatidão de contas. Transferiu-se com a família para Valadolid, em 1604 obteve privilégio para editar a primeira parte do D. Quixote e ainda no final de sua vida esteve às voltas com a justiça. Em 1613, deu-se a publicação de Novelas Exemplares, em 1615 da segunda parte do D. Quixote, e sua morte em 1616 (4).

(2). - A palavra aqui é utilizada no sentido de mascarar a visão concreta dos problemas, melhorando a realidade, ou, ao menos, fugindo dela.

(3) . - Pfandl (L.). - Historia de la literatura Nacional Española en la Edad de Oro, Barcelona, Edit. Gustavo Gili, 1952.

(4). - Cassou (J.). - Cervantes: un hombre y una época, Buenos Aires, Ed. Siglo Veinte, 1958, pp. 34-38. 
Quanto às tendências culturais indica Marcel Bataillon (5) que Cervantes recebeu de Lopez de Hoyos lições confidenciais de um erasmismo condenado, e Menendez y Pelayo, que sua obra guarda afinidades com a literatura polêmica do Renascimento.

Ainda aponta Bataillon (6) que não se deve estranhar que as formas prediletas da literatura humanística tenham se imposto a Cervantes nos momentos em que criava a novela espanhola, com plena consciência de continuar a obra de Bocaccio, ultrapassando-a.

A análise lúcida de Bataillon mostra ainda também que não é de causar espanto a posição favorável de Cervantes diante da expulsão dos mouros, na medida em que para um humanista cristão a guerra contra o Islão não era uma calamidade se comparada à guerra civil entre católicos e protestantes (7).

Importante, ainda, seria a partir dessa colocação de Bataillon rcalizarmos a análise de La Gitanilla na tentativa de perceber como Cervantes enxergava os diversos grupos sociais, entre eles especialmente o formado pelos gitanos, minoria não integrada e discriminada pela sociedade global.

II. - Grupos sociais e o problema das minorias.

Cervantes colocou os gitanos como tema de uma de suas Novelas Exemplares, criticando-os inicialmente, identificando-os aos ladrões, com tara de roubo hereditária e ressalvando para um de seus membros, Preciosa, qualidades como dicreção, desenvoltura, cortesia, honestidade etc.

O caráter interesseiro da avó cigana fica marcado, bem como seu modo de explorar as qualidades da neta (8). Cervantes dá a medida do comportamento popular e do preconceito existente contra os ciganos, ao descrever a entrada de Preciosa em Madri (9).

Os tipos sociais colocados sucessivamente (tenentes, pajem, cavalheiros, escudeiro, corregedor, labradoras, alcaide etc.) aparecem dentro de uma visão integrada e hierarquizada do mundo, sintoma claro de que Cervantes não escapava ao seu tempo. Sua visão da vip. 400 .

(5). - Bataillon (M.) - - Erasmo y España, Mexico, F. C. E., 1950,

(6). - Bataillon (M.) . - Op. cit., p. 402.

(7). - Idem, p. 421 .

(8). - Cervantes (M. de) . - Novelas Exemplares, Buenos Aires, Espasa-Calpe, 1965 , p. 9.

(9). - Idem, pp. 10, 11. 
da social e das relações entre os diversos grupos indicava um certo ideal aristocrático de vida, que já anunciava as características da sociedade do Barroco (10).

Esse ideal aristocrático pode ser pressentido em muitas passagens de La Gitanilla. A personagem central, Preciosa, não era na verdade uma autêntica cigana. Da mesma forma, Andrés é valorizado "enquanto" filho de nobre (11). E, até mesmo o pajem, aquele que fez versos para a Gitanilla, era na verdade um conde. Assim, por detrás dos personagens há realidades sociais não identificáveis à primeira vista; de qualquer forma, o final feliz de toda a trama dá-se no momento em que os heróis assumem sua verdadeira condição social. (12).

Deve-se chamar a atenção para certos valores sociais que repontam a cada passo do texto de Cervantes. Poderíamos mencionar, desde logo, a descrição muito cuidada do cavalheiro (13), ou então, a apresentação minuciosa e positiva dos tipos da ordem estabelecida (exemplo: corregedor, corregedora entre outros), em contraposição flagrante com a minoria dos ciganos à qual pertencia Preciosa. São eles portadores de defeitos, como a cobiça, e o elemento de comparação é, sem dúvida, a "boa sociedade". O choque de valores é visivel até mesmo quanto à concepção da caridade (14).

Se Preciosa aparece por vezes revestida de valores positivos, esses valores são aqueles das camadas dominantes, às quais pertencia Andrés (além dela própria, como depois se verificou no desenrolar da trama). Preciosa faz a imagem da "boa gitana": tem problemas de honra (15), sabe ler e escrever (16), canta "romances" cuja temática não comporta valores sociais de seu grupo (17) e, revelando um indisfarçável problema de ascensão acha que a pobreza é inimiga do amor (18). Não será, pois, com surpresa, que vamos encontrá-la preocupada com o problema do dinheiro (19).

A leitura de La Gitanilla além de sugerir o estudo desses valores sociais, permite surpreender indícios da crise econômica espa-

(10). - Veja-se o capítulo "Formación aristocrática de la vida y estilo barroco", in Alfred Weber, Historia de la Cultura, Mexiç, F. C. E., 1960.

(11). - Cervantes (M. de). - Op. cit., p. 29.

(12). - Idem, p. 60 ou pp. 48-49.

(13). - Idem, p. 23 .

(14). - Idem, p. 16 .

(15). - lbidem.

(16). - Idem, p. 19.

(17). - Idem, pp. 13, 14, 15.

(18). - Idem, p. 18.

(19). - Idem, p. 19. 
nhola. Bastará lembrar que na casa do Tenente, em que fora convidada a cantar, o dinheiro inexistia para pagá-la (20). Como indicamos, anteriormente, tendo como base os trabalhos de Pierre Vilar, a economia espanhola atravessava um de seus momentos mais críticos, depois de ter atingido um apogeu no período anterior.

Não se deve deixar de mencionar, ainda, certas manifestações que ocorriam na vida religiosa da época. Uma visão romanceada da bruxaria é apresentada (21), indício de que a religiosidade continuava atravessando as consciências mais sensíveis da época.

$$
\text { III. - Conclusão. }
$$

La Gitanilla, obra através da qual uma minoria é apresentada, reflete no plano literário a maneira pela qual a sociedade global enxergava essa minoria não integrada. Vimos que a perspectiva de Cervantes estava calcada na ideologia das camadas dominantes, com ideais aristocratizantes (22). Pode-se verificar como o povo discriminava os ciganos, da mesma forma que a justiça oficial se manifestava duramente contra os mesmos (22). Um personagem como Andrés quer casar com Preciosa para dela fazer, como ele prcprio diz, mi igual y mi señora (24). Nessa mesma linha, Preciosa é recebida na casa do Tenente como elemento proveniente de um "corpo social estranho" (25).

Vendo a questão no ângulo dos ciganos, basta mencionar que Preciosa desejava a união com Andrés, resguardando porém sua independência e exigindo que o filho de um nobre se integrasse em seu grupo (26).

De qualquer forma, esta obra de Cervantes permite verificar como uma minoria era percebida nos horizontes dos setores dominantes. Bastará mencionar que Cervantes despende ao menos três pági-

(20). - Idem, p. 22.

(21). - Idem, p. 17.

(22). - Cassou (J.). - Op. cit., p. 35. Neste trabalho é mancionado - momento da volta de Cervantes, da batalha de Lepanto; tem êle cartas de recomendação ao rei, dadas por D. João de Austria e pelo vice-rei da Sićlia. Nessas cartas é mencionado como um príncipe: sua prisão pelos bérberes e o equívoco das cartas lhe tiram a oportunidade de "hacer figura noble y mostrar su corazón valiente".

(23). - Cervantes, - op. cit., p. 57.

(24). - Idem, p. 24.

(25). - Idem, p. 21-22.

(26). - Idem, pp. 26 e 24 respectivamente. 
nas de sua novela para descrever - à sua maneira, é claro - costumes da comunidade gitana (27).

Pelo esforço realizado nesta análise, pode-se depreender que o ideal aristocrático de vida informava largamente a concepção de mundo de Cervantes. Preciosa só pôde se tornar personagem principal da novela, não porque fosse cigana, mas porque era nobre. Se Preciosa fosse realmente uma cigana, a solução final da trama nunca teria sido favorável a Andrés, filho de nobre. ' $E$ ' ela quem retorna ao seu meio", e não Andrés quem adere totalmente à vida gitana.

IV. - Bibliografia Sumária.

1. - Cervantes (Miguel de). - Novelas Exemplares, Buenos Aires, Espasa-Calpe, 1965.

2. - Vilar (Pierre). - Crecimiento y Desarrollo, Barcelona, Ed. Ariel, 1964 .

3. - Cassou (Jean). - Cervantes: un hombre y una época, Buenos Aires, Ed. Siglo Veinte, 1958.

4. - Reglá (J.) e Céspedes del Castillo (Guillermo). - Historia Social y Economica de España y America (dirigida por Vicens Vives), Barcelona, Edit. Teide, t. III, 1957.

5. - Bataillon (Marcel). - Erasmo y España, Mexico, Fondo de Cultura Economica, 1950, 2 vols.

6. - Pfandl (L.). - Historia de la literatura Nacional Española en la Edad de Oro, Barcelona, Edit. Gustavo Gili, 1952.

7. - Weber (Alfred). - Historia de la Cultura, Mexico, Fondo de Cultura Economica, 1960.

(27). - Idem, pp. 36 a 39. 